\title{
Composição bromatológica e digestibilidade de cana-de- açúcar colhida em duas épocas do ano
}

\author{
Chemical composition and digestibility of sugarcane harvested at two periods of the year
}

\author{
Marina Vieira de CARVALHO ${ }^{1}$; Paulo Henrique Mazza RODRIGUES ${ }^{1}$; Maria Lúcia Pereira LIMA²; \\ Ivan Antônio dos ANJOS ${ }^{3}$; Marcos Guimarães de Andrade LANDELL'; Marcos Veiga dos SANTOS ${ }^{1}$; \\ Luis Felipe PRADA E SILVA ${ }^{1}$ \\ ${ }^{1}$ Departamento de Nutrição e Produção Animal da Faculdade de Medicina Veterinária e Zootecnia da Universidade de São Paulo, \\ Pirassununga-SP \\ ${ }^{2}$ Apta Regional, APTA, SAA-SP, Ribeirão Preto-SP \\ ${ }^{3}$ Centro Avançado da Pesquisa Tecnológica do Agronegócio de Cana - IAC/APTA, Ribeirão Preto-SP
}

\begin{abstract}
Resumo
Objetivou-se com este estudo avaliar o efeito da época de corte sobre a composição bromatológica e digestibilidade in vitro de genótipos de cana-de-açúcar, comparar a composição bromatológica e digestibilidade in vitro das frações colmo e folhas, e estabelecer possíveis correlações entre composição química e digestibilidade in vitro da planta inteira de genótipos da cana-de-açúcar. Nove genótipos foram colhidos em maio e setembro de 2006. Em maio, somente a fração planta inteira foi analisada, em setembro foram separados em colmos, folhas ou planta inteira para determinação da composição bromatológica, sacarose (POL) e digestibilidade in vitro. Colmos apresentaram menor teor de fibra em detergente neutro (FDN) e lignina na MS, e maior digestibilidade in vitro da matéria seca (DIVMS) do que folhas. Em contrapartida, apresentaram menor digestibilidade in vitro da FDN (DIVFDN), maior teor de lignina na FDN e menor concentração de proteína bruta (PB). Houve redução no teor e digestibilidade da FDN com o avanço da maturidade, enquanto que DIVMS, POL e lignina aumentaram. A DIVMS se mostrou negativamente correlacionada com FDN e FDN/POL, porém não houve correlação entre DIVFDN e FDN ou FDN/POL. Conclui-se que o avanço da maturidade promoveu redução na DIVFDN e aumento na DIVMS, não existindo correlação genética entre acúmulo de açúcar e digestibilidade in vitro da fibra. Os dados deste artigo indicam não ser esperado que a seleção de genótipos com maior DIVFDN do colmo altere o teor de açúcar do mesmo.
\end{abstract}

Palavras-chave: Açúcar. Colmo. Fibra. Lignina. Saccharum officinarum.

\begin{abstract}
The objectives of this study were to evaluate the effect of time of harvest on chemical composition and in vitro digestibility of sugarcane genotypes, to compare chemical composition and in vitro digestibility of the stem and leaf fractions, and to determine possible correlations between chemical composition and in vitro digestibility of the whole plant in sugarcane genotypes. Nine genotypes were harvested in May and September of 2006. In May, only the whole-plant fraction was analyzed, in September the genotypes were separated in stems, leaves or whole-plant for determination of chemical composition, sucrose (POL) and in vitro digestibility. Stems had lower neutral detergent fiber (NDF) and lignin in the DM, and greater in vitro dry matter digestibility (IVDMD) than leaves. However, stems had lower in vitro NDF digestibility (IVNDFD), higher lignin in the NDF and lower crude protein (CP). The NDF and IVNDFD were reduced with advanced maturity, while IVDMD, POL and lignin were increased. IVDMD was negatively correlated with NDF and NDF/POL, however there was no correlation between IVFDND and NDF or NDF/POL. It can be concluded that with the advance in maturity the IVNDFD was reduced and IVDMD was increased, and there was no genetic correlation between accumulation of sugar and in vitro fiber digestibility. Data from this study indicate that it is not expected that selection of genotypes with greater stem IVNDFD would alter the sugar content of the plant.
\end{abstract}

Keywords: Fiber. Lignin. Saccharum officinarum. Stems. Sugar.

\section{Introdução}

Apesar do pior valor nutritivo em relação às silagens de milho e sorgo ${ }^{1}$, a cana-de-açúcar apresenta características de grande interesse aos pecuaristas, pela elevada produção de massa seca por hectare, fa-

\section{Correspondência para:}

Prof Dr. Luis Felipe Prada e Silva

Av. Duque de Caxias Norte, 225

Depto. de Nutrição e Produção Animal, Pirassununga-SP. CEP: 13635-900

e-mail: lfpsilva@usp.br

Recebido: 26/06/2009

Aprovado: 01/04/2010 
cilidade de cultivo e persistência da cultura, boa aceitação pelos animais, elevado teor de carboidratos solúveis e menor custo de produção ${ }^{2,3}$. Ao contrário de outras plantas forrageiras, a cana não reduz seu valor nutritivo de forma expressiva no período de estiagem, e destaca-se pelo aumento no teor de sacarose nesta época do $\mathrm{ano}^{4}$.

A ocorrência de variações nos parâmetros de qualidade nutricional das plantas forrageiras segundo a espécie, variedade, estágio de maturação, parte da planta considerada (colmo ou folhas), fertilidade do solo, entre outros, já é bastante conhecida e possibilita o emprego do melhoramento genético como ferramenta para a manipulação da qualidade das forrageiras ${ }^{5}$. No entanto, o melhoramento da cana-de-açúcar tem se direcionado principalmente para os objetivos industriais de produção de açúcar e álcool combustível, os quais buscam apenas plantas com maiores teores de sacarose ${ }^{6}$. Porém, além do teor de sacarose, a qualidade da fibra é de fundamental importância para a nutrição de ruminantes, evidenciando a necessidade do estabelecimento de critérios de seleção visando especificamente à alimentação animal ${ }^{2}$.

A principal limitação para o uso da cana-de-açúcar na nutrição de animais de elevado potencial de produção é a baixa digestibilidade da fibra (FDN), aliado ao baixo teor de proteína bruta ${ }^{7}$. Outro fator de importante efeito na qualidade nutricional da cana-deaçúcar é a idade da planta, uma vez que as diferentes variedades apresentam curvas de maturação distintas, com variações na porcentagem de sacarose dentro da curva $^{1}$.

Este estudo teve como objetivos avaliar o efeito da época de corte sobre a composição bromatológica e digestibilidade in vitro de genótipos de cana-de-açúcar, comparar a composição bromatológica e digestibilidade in vitro das frações colmo e folhas, e estabelecer possíveis correlações entre composição química e digestibilidade in vitro da planta inteira de genótipos da cana-de-açúcar. É importante salientar que não se objetivou a classificação dos genótipos, mas sim a determinação da existência de variabilidade genética para os parâmetros estudados.

\section{Material e Método}

O experimento de avaliação de clones foi estabelecido no Centro de Cana-de-Açúcar, do Instituto Agronômico de Campinas, localizado em Ribeirão Preto-SP. Os genótipos estudados, provenientes do Programa de Melhoramento Genético de Cana-deAçúcar do Instituto Agronômico de Campinas, foram obtidos por intermédio de hibridações realizadas em 2004, em Camamu - BA.

Os genótipos foram plantados na semana de 4 a 8 de julho de 2005 e irrigados até o final do período seco (setembro de 2005). As parcelas consistiam de duas linhas de cana com espaçamento de 1,4 metro e com quatro metros de comprimento para cada genótipo. A cada idade de corte, 15 plantas inteiras, selecionadas aleatoriamente, foram colhidas por parcela. Assim, existiam nove repetições (genótipos) para determinação do efeito da época de corte sobre a composição química e digestibilidade das frações da cana-deaçúcar. Existiam somente duas repetições (épocas de corte) para avaliação do efeito de genótipo.

Foram realizadas seleções nos anos de 2005 e 2006, elegendo-se clones com características agronômicas como: elevado teor de açúcares, uniformidade de parâmetros biométricos de produção, hábito de crescimento ereto, capacidade de rebrotação no período de seca, resistência à ferrugem da folha (Puccinia melanocephala), dentre outras. Além dos dados de produtividade, estes materiais foram avaliados quanto ao teor de fibra em detergente neutro (FDN), sacarose aparente (POL), celulose e lignina.

Com base nos resultados obtidos, sete clones e duas variedades comerciais foram selecionados para o presente estudo, visando à avaliação da digestibilidade in 
vitro da matéria seca (MS) e da FDN das frações colmo, folha e planta inteira. Foram selecionados três clones com baixa relação FDN/POL (2004-2102, 2004-2035, 2004-2263), dois clones com relação FDN/POL intermediária (2004-2158 e 2004-2024), dois clones com teores altos de FDN (2004-2120 e 2004-2168) e duas variedades comerciais, incluídas no estudo, como parâmetros de controle (IAC86-2480 e IACSP93-3046).

Os clones e as variedades foram colhidos nos meses de maio e setembro de 2006. O corte foi feito rente ao solo. Somente na colheita de setembro foram separadas as frações colmo e folha, portanto os efeitos de época de corte se referem somente à fração planta inteira. As frações foram separadas, trituradas e secas em estufa de ventilação forçada a $55 \pm 5^{\circ} \mathrm{C}$ por $72 \mathrm{~h}$. Após moagem em moinho, com peneira com crivo de um milímetro, as amostras foram acondicionadas em frascos de vidro.

Os teores de proteína bruta $(\mathrm{PB})$ foram analisados segundo $\mathrm{AOAC}^{8}$, os teores de fibra em detergente neutro (FDN) segundo Van Soest, Robertson e Lewis ${ }^{9}$ sem adição de $\alpha$-amilase e sem adição de sulfito de sódio. Os teores de fibra em detergente ácido (FDA) e lignina em detergente ácido (LDA) seguiram a metodologia de Goering e Van Soest ${ }^{10}$. A concentração de lignina foi expressa tanto em termos de $\%$ de MS (LDA-MS) quanto em \% de FDN (LDAFDN), para estimar a correlação com digestibilidade da MS e da FDN.

A concentração de POL foi determinada segundo Fernandes ${ }^{11}$. Para a determinação da digestibilidade in vitro da MS (DIVMS) e da FDN (DIVFDN), um grama de amostra foi incubado por $30 \mathrm{~h}$ a $39^{\circ} \mathrm{C}$ com solução tampão de Goering ( $40 \mathrm{~mL}$ ) e líquido ruminal $(10 \mathrm{~mL})$, segundo protocolo de Goering e Van Soest ${ }^{10}$. Apenas a fase fermentativa foi conduzida, sendo determinado o teor de FDN após 30 h de incubação. O líquido ruminal foi retirado de três bovinos fistulados no rúmen recebendo dieta à base de cana-de-açúcar mais concentrado (30\% da MS).

Para a comparação das frações colmo, folhas e planta inteira, somente os dados da coleta de setembro foram utilizados. Os dados foram analisados considerando-se o delineamento inteiramente ao acaso com nove repetições (clones). A análise estatística foi realizada utilizando-se o procedimento GLM do software estatístico $\mathrm{SAS}^{12}$, segundo o modelo: $\mathrm{Y}=\mu+$ Tecido + Clone + e.

Para determinação do efeito da época de corte sobre a composição bromatológica da planta inteira, considerou-se o delineamento inteiramente ao acaso com nove repetições (clones). A análise estatística foi realizada utilizando-se o procedimento GLM do SAS ${ }^{12}$, segundo o modelo: $\mathrm{Y}=\mu+$ Idade + Clone $+\mathrm{C}$. O procedimento PDIFF foi utilizado para comparação das médias das épocas de corte, e o efeito de genótipo foi testado pelo teste-F com duas repetições (épocas de corte). Utilizou-se nível de significância de 5\% para todos os testes realizados.

\section{Resultados}

Avaliando-se o teor de FDN, PB, lignina, digestibilidade in vitro da matéria seca (DIVMS) e a digestibilidade in vitro da FDN (DIVFDN) das frações colmo, folhas e planta inteira de nove genótipos de cana-deaçúcar (sete clones e duas variedades) colhidos aos 15 meses, observou-se diferença significativa de tecido para todas as variáveis estudadas (Tabela 1).

O colmo apresentou menor teor total de FDN (38,2\% MS), quando comparado com as folhas $(68,7 \%$ MS) e com a planta inteira (41,6\% MS), e maior DIVMS $(66,3 \%$ MS) que as folhas $(47,7 \%$ MS), sendo esta igual, no entanto, à apresentada pela planta inteira $(64,9 \% \mathrm{MS})$. Os colmos apresentaram menor teor de LDA-MS (5,6\% MS) que as folhas (6,5\% MS), não diferindo da planta inteira (5,3\% MS); no entanto, observou-se teor de LDA-FDN significativamente maior 
nos colmos $(14,8 \%$ FDN) do que nas folhas $(9,4 \%$ FDN) e planta inteira (12,7\% FDN). O colmo apresentou DIVFDN em média 50,4\% inferior à fração folhas. As folhas apresentaram maior teor de PB $(4,4 \%)$ que os colmos e a planta inteira (1,6 e 1,8\%, respectivamente), os quais não diferiram entre si (Tabela 1).

Avaliando-se a existência de variabilidade genética na composição química e digestibilidade in vitro da planta inteira, nos nove genótipos de cana-de-açúcar, independente da idade de corte (11 ou 15 meses), observou-se efeito de genótipo para as variáveis FDN, LDA-MS, FDN/POL, LDA-FDN e DIVMS, sendo que as variações encontradas nos teores de FDN, lignina e na DIVMS, foram significativas a $1 \%$ de probabilidade. No entanto, não houve efeito de genótipo nos teores de POL, PB e na DIVFDN (Tabela 2).
O estudo das correlações entre a composição química e a digestibilidade in vitro da planta inteira dos nove genótipos de cana-de-açúcar estudados, quando o corte foi realizado em maio (11 meses) e quando o corte foi realizado em setembro (15 meses), demonstrou que a DIVMS apresentou alta correlação negativa com o teor de FDN e de LDA-MS, em ambas as épocas de corte, e com a relação FDN/POL, quando o corte foi realizado em maio (Tabelas 3 e 4). Não houve correlação entre DIVMS e teor de POL em nenhuma das duas épocas de corte (Tabelas 3 e 4). A DIVFDN não apresentou correlação com o teor de FDN, de LDA-MS, de sacarose (POL) ou com a relação FDN/ POL, contudo, apresentou correlação negativa com a concentração de LDA-FDN em ambas as épocas de corte (Tabelas 3 e 4).

Tabela 1 - Composição química e digestibilidade in vitro de tecidos de nove genótipos de cana-de-açúcar, colhidos em setembro ${ }^{1}$

\begin{tabular}{|c|c|c|c|c|c|c|}
\hline \multirow{2}{*}{ Tecidos } & $\mathrm{FDN}^{2}$ & $\mathrm{~PB}^{3}$ & LDA-MS $^{4}$ & DIVMS $^{5}$ & LDA-FDN $^{6}$ & DIVFDN $^{7}$ \\
\hline & \multicolumn{4}{|c|}{ - } & \multicolumn{2}{|c|}{ - } \\
\hline Folha & $68,7^{\mathrm{A}}$ & $4,4^{\mathrm{A}}$ & $6,5^{\mathrm{A}}$ & $47,7^{\mathrm{B}}$ & $9,4^{\mathrm{C}}$ & $23,9^{\mathrm{A}}$ \\
\hline Colmo & $38,2^{\mathrm{C}}$ & $1,6^{\mathrm{B}}$ & $5,6^{\mathrm{B}}$ & $66,3^{\mathrm{A}}$ & $14,8^{\mathrm{A}}$ & $11,9^{\mathrm{C}}$ \\
\hline Planta inteira & $41,6^{\mathrm{B}}$ & $1,8^{\mathrm{B}}$ & $5,3^{\mathrm{B}}$ & $64,9^{\mathrm{A}}$ & $12,7^{\mathrm{B}}$ & $15,8^{\mathrm{B}}$ \\
\hline E.P.M. ${ }^{8}$ & 0,93 & 0,33 & 0,17 & 0,80 & 0,38 & 0,97 \\
\hline
\end{tabular}

${ }^{1}$ Médias na mesma coluna seguidas de letras diferentes diferem estatisticamente pelo teste de Tukey $(P<0,05) .{ }^{2}$ Fibra em detergente neutro.

${ }^{3}$ Proteína bruta. ${ }^{4}$ Lignina em detergente ácido (\%MS). ${ }^{5}$ Digestibilidade in vitro da matéria seca (30h). ${ }^{6}$ Lignina em detergente ácido (\%FDN).

${ }^{7}$ Digestibilidade in vitro da FDN (30h). ${ }^{8}$ Erro padrão da média

Tabela 2 - Média da composição química e digestibilidade in vitro da planta inteira de nove genótipos de cana-deaçúcar, colhidos em duas épocas do ano

\begin{tabular}{|c|c|c|c|c|c|c|c|c|}
\hline \multirow{2}{*}{ Clones } & $\mathrm{FDN}^{1}$ & $\mathrm{~PB}^{2}$ & ${\mathrm{LDA}-\mathrm{MS}^{3}}^{3}$ & DIVMS $^{4}$ & $\mathrm{POL}^{5}$ & FDN/POL & LDA-FDN $^{6}$ & DIVFDN $^{7}$ \\
\hline & \multicolumn{4}{|c|}{ - $\%$ MS - - } & \multicolumn{2}{|l|}{$\% \mathrm{MO}$} & \multicolumn{2}{|c|}{ - $\%$ FDN - - } \\
\hline IACSP93-3046 & 50,6 & 2,1 & 5,9 & 61,2 & 16,3 & 3,2 & 11,6 & 23,8 \\
\hline IAC86-2480 & 41,9 & 2,4 & 4,1 & 67,6 & 15,6 & 2,8 & 9,9 & 22,4 \\
\hline 2004-2102 & 41,1 & 1,9 & 4,4 & 68,0 & 17,4 & 2,6 & 10,8 & 22,0 \\
\hline $2004-2168$ & 70,4 & 3,3 & 7,8 & 45,4 & 14,5 & 5,3 & 11,4 & 21,1 \\
\hline $2004-2263$ & 44,7 & 1,9 & 5,1 & 64,0 & 16,3 & 3,4 & 11,6 & 19,1 \\
\hline 2004-2035 & 43,5 & 2,2 & 5,3 & 64,1 & 15,7 & 2,8 & 12,1 & 17,4 \\
\hline $2004-2158$ & 53,8 & 2,4 & 6,3 & 55,2 & 16,9 & 2,2 & 11,9 & 15,7 \\
\hline $2004-2120$ & 43,5 & 2,0 & 5,4 & 63,3 & 16,7 & 2,6 & 12,6 & 15,2 \\
\hline 2004-2024 & 48,5 & 2,0 & 6,2 & 58,6 & 14,9 & 3,3 & 12,9 & 14,5 \\
\hline E.P.M. ${ }^{8}$ & 2,3 & 0,3 & 0,2 & 1,5 & 1,2 & 0,4 & 0,4 & 2,4 \\
\hline Efeito de genótipos ${ }^{9}$ & $* *$ & ns & $* *$ & $* *$ & ns & $*$ & * & ns \\
\hline
\end{tabular}

${ }^{1}$ Fibra em detergente neutro. ${ }^{2}$ Proteína bruta. ${ }^{3}$ Lignina em detergente ácido (\%MS). ${ }^{4}$ Digestibilidade in vitro da matéria seca (30h). ${ }^{5}$ Porcentagem de sacarose aparente na cana. ${ }^{6}$ Lignina em detergente ácido (\%FDN). ${ }^{7}$ Digestibilidade in vitro da FDN (30h). ${ }^{8}$ Erro padrão da média. ${ }^{9}$ Teste-F para efeito principal de genótipos. ${ }^{\star} \mathrm{e}^{\star *}$ Significativo a $5 \%$ e a $1 \%$ de probabilidade, respectivamente. ${ }^{\text {ns Não significativo }}$ 
Tabela 3 - Coeficientes de correlação de Pearson entre composição química e digestibilidade in vitro da planta inteira de nove genótipos de cana-de-açúcar, colhidos em maio

\begin{tabular}{lcccccccc}
\hline \multicolumn{1}{c}{ Parâmetros } & $\mathrm{POL}^{1}$ & $\mathrm{FDN}^{2}$ & FDN/POL & $\mathrm{PB}^{3}$ & LDA-MS $^{4}$ & LDA-FDN $^{5}$ & DIVMS $^{6}$ & DIVFDN $^{7}$ \\
\hline POL & 1 & $-0,53^{\text {ns }}$ & $-0,75^{*}$ & $-0,49^{\text {ns }}$ & $-0,33^{\text {ns }}$ & $0,42^{\text {ns }}$ & $0,50^{\text {ns }}$ & $-0,40^{\text {ns }}$ \\
FDN & & 1 & $0,96^{* *}$ & $0,80^{*}$ & $0,92^{* *}$ & $0,01^{\text {ns }}$ & $-0,99^{* *}$ & $0,41^{\text {ns }}$ \\
FDN/POL & & & 1 & $0,79^{*}$ & $0,82^{*}$ & $-0,13^{\text {ns }}$ & $-0,94^{* *}$ & $0,44^{\text {ns }}$ \\
PB & & & 1 & $0,64^{\text {ns }}$ & $-0,24^{\text {ns }}$ & $-0,75^{*}$ & $0,63^{\text {ns }}$ \\
LDA-MS & & & & & 1 & $0,41^{\text {ns }}$ & $-0,96^{* *}$ & $0,03^{\text {ns }}$ \\
LDA-FDN & & & & & & 1 & $-0,15^{\text {ns }}$ & $-0,85^{* *}$ \\
DIVMS & & & & & & & & $-0,27^{\text {ns }}$ \\
\hline
\end{tabular}

${ }^{1}$ Porcentagem de sacarose aparente na cana. ${ }^{2}$ Fibra em detergente neutro. ${ }^{3}$ Proteína bruta. ${ }^{4}$ Lignina em detergente ácido (\%MS). ${ }^{5}$ Lignina em detergente ácido (\%FDN). ${ }^{6}$ Digestibilidade in vitro da matéria seca (30h); ${ }^{7}$ Digestibilidade in vitro da FDN (30h). * $\mathrm{e}^{* *}$ Significativo a $5 \%$ e a $1 \%$ de probabilidade, respectivamente. ${ }^{\text {ns }}$ Não significativo

Tabela 4 - Coeficientes de correlação de Pearson entre composição química e digestibilidade in vitro da planta inteira de nove genótipos de cana-de-açúcar, colhidos em setembro

\begin{tabular}{|c|c|c|c|c|c|c|c|c|}
\hline Parâmetros & $\mathrm{POL}^{1}$ & $\mathrm{FDN}^{2}$ & FDN/POL & $\mathrm{PB}^{3}$ & LDA-MS $^{4}$ & LDA-FDN $^{5}$ & DIVMS $^{6}$ & DIVFDN $^{7}$ \\
\hline POL & 1 & $0,29^{\text {ns }}$ & $-0,60^{\text {ns }}$ & $-0,04^{\mathrm{ns}}$ & $0,01^{\mathrm{ns}}$ & $-0,34^{\mathrm{ns}}$ & $-0,12^{\mathrm{ns}}$ & $0,26^{\mathrm{ns}}$ \\
\hline FDN & & 1 & $0,59^{\text {ns }}$ & $0,14^{\mathrm{ns}}$ & $0,88^{* *}$ & $0,48^{\mathrm{ns}}$ & $-0,87^{\star *}$ & $-0,27^{\mathrm{ns}}$ \\
\hline FDN/POL & & & 1 & $0,17^{\mathrm{ns}}$ & $0,74^{*}$ & $0,66^{\mathrm{ns}}$ & $-0,63^{\text {ns }}$ & $-0,36^{\mathrm{ns}}$ \\
\hline PB & & & & 1 & $-0,02^{\mathrm{ns}}$ & $-0,25^{\mathrm{ns}}$ & $-0,02^{\mathrm{ns}}$ & $0,21^{\mathrm{ns}}$ \\
\hline LDA-MS & & & & & 1 & $0,84^{\star *}$ & $-0,95^{\star *}$ & $-0,62^{\mathrm{ns}}$ \\
\hline LDA-FDN & & & & & & 1 & $-0,76^{*}$ & $-0,82^{*}$ \\
\hline DIVMS & & & & & & & 1 & $0,71^{*}$ \\
\hline
\end{tabular}

${ }^{1}$ Porcentagem de sacarose aparente na cana. ${ }^{2}$ Fibra em detergente neutro. ${ }^{3}$ Proteína bruta. ${ }^{4}$ Lignina em detergente ácido (\%MS). ${ }^{5}$ Lignina em detergente ácido (\%FDN). ${ }^{6}$ Digestibilidade in vitro da matéria seca (30h); ${ }^{7}$ Digestibilidade in vitro da FDN (30h). * $\mathrm{e}^{* *}$ Significativo a $5 \%$ e a $1 \%$ de probabilidade, respectivamente. ${ }^{\text {ns }}$ ão significativo

A época de corte influenciou todos os parâmetros avaliados, exceto o teor de LDA-MS (Figura 1). Houve redução no teor de FDN, PB, FDN/POL e DIVFDN, enquanto os teores de POL, LDA-FDN e a DIVMS aumentaram com o avançar da maturidade (Figura 1).

\section{Discussão}

O colmo responde por mais de $80 \%$ do total de matéria seca da cana-de-açúcar madura ${ }^{13}$, sendo assim é de se esperar que a qualidade do colmo influencie mais a qualidade da planta inteira do que as folhas. Para todos os parâmetros avaliados, os resultados obtidos na planta inteira se aproximaram mais dos valores encontrados para o colmo, evidenciando a importância do valor nutritivo desta fração em programas de melhoramento genético da cana-de-açúcar, visando à alimentação animal. Sallas et al. ${ }^{14}$ já haviam reportado que, no que diz respeito à composição química e à digestibilidade, o colmo é a parte mais interessante da cana-de-açúcar, exceto em seu teor de proteína.

O colmo apresentou menor teor total de FDN e LDA-MS, e maior DIVMS que as folhas, semelhante aos resultados reportados por Banda e Valdez ${ }^{13}$, que obtiveram 70,5 \% de DIVMS para colmos de variedades de cana-de-açúcar colhidas aos 16 meses; e por Rodrigues, Primavesi e Esteves ${ }^{15}$, que avaliando 11 variedades de cana-de-açúcar colhidas também aos 15 meses pós-plantio, observaram teores de FDN variando de 40,5 a 48,9\% nos colmos e de 76,6 a 80,8 \% nas folhas, além de maior DIVMS (75,5\%) para a fração colmo em relação à folha $(51,4 \%)$. O 


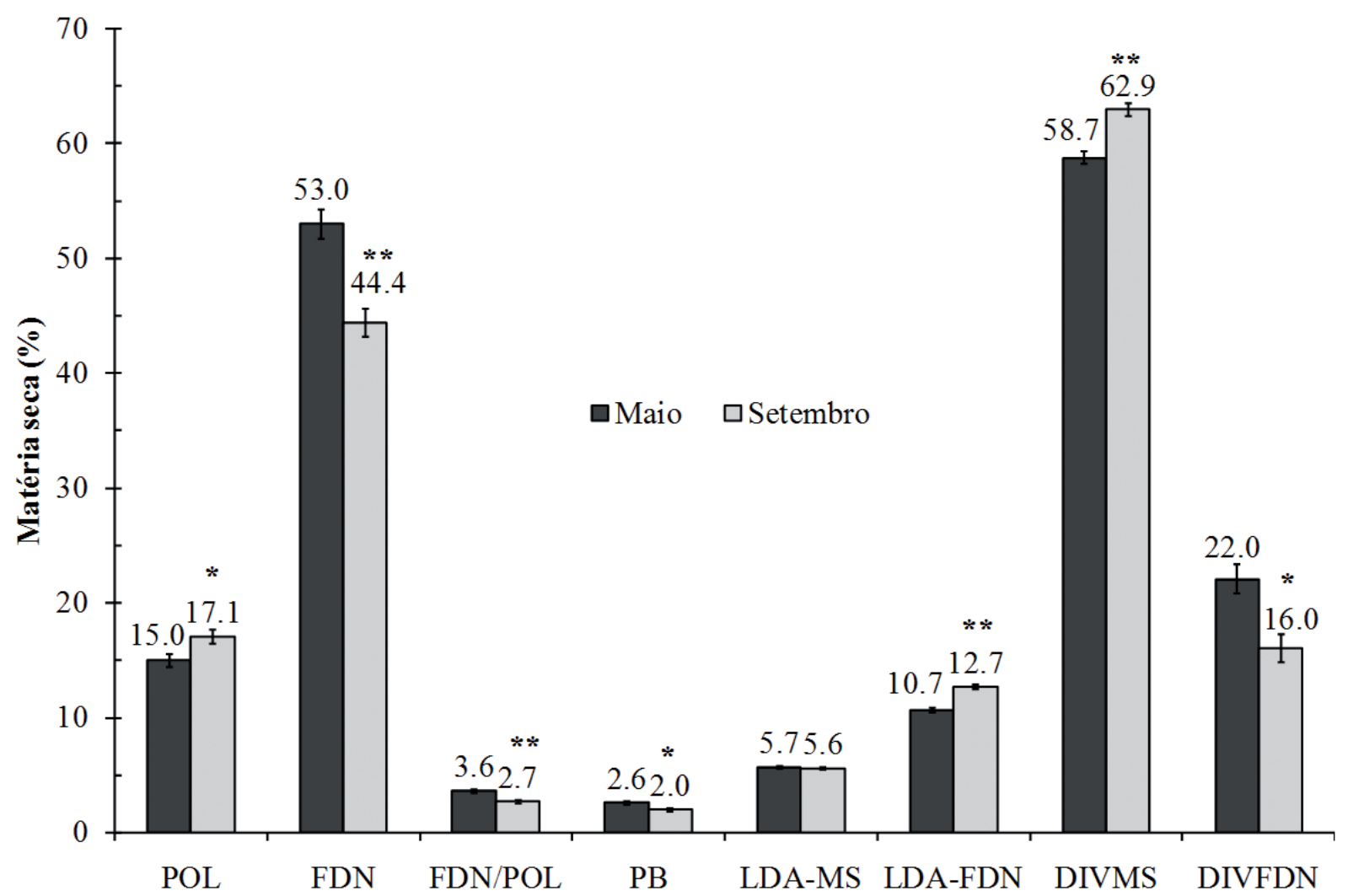

Figura 1 - Efeito da época de corte sobre a composição bromatológica e digestibilidade in vitro da planta inteira de canade-açúcar (média de nove clones). POL = Sacarose aparente (\% MO da cana); FDN = Fibra em detergente neutro; $\mathrm{PB}=$ proteína bruta, LDA-MS = lignina em detergente ácido (\%MS), LDA-FDN = lignina em detergente ácido (\%FDN), DIVFDN = digestibilidade in vitro da matéria seca (30h); DIVFDN = digestibilidade in vitro da FDN (30h). ${ }^{*} \mathrm{e}^{* *}$ Significativo a $5 \%$ e a $1 \%$ de probabilidade, respectivamente

maior teor de açúcares solúveis no colmo explica o menor teor de FDN e a maior DIVMS desta fração. Apesar de apresentar maior DIVMS do que folhas, o colmo apresentou menor digestibilidade da fibra, o que pode ser explicado pela maior lignificação da parede celular desta fração, evidenciado pelo maior teor de LDA-FDN.

Tais resultados sugerem que do ponto de vista da nutrição de ruminantes, a digestibilidade da fibra seria fator mais limitante ao desempenho animal do que a digestibilidade da matéria seca, visto que o colmo apresenta alto valor de DIVMS e baixo valor de DIVFDN.

Quando os genótipos de cana-de-açúcar estudados foram considerados separadamente, apesar de se observar diferença nos teores de FDN, LDA-MS,
DIVMS, relação FDN/POL e LDA-FDN, não foi observada diferença na DIVFDN, entretanto houve variação numérica média de 14,5 a $23,8 \%$ na DIVFDN. A aparente ausência de efeito de genótipo sobre a digestibilidade da fibra da cana-de-açúcar, neste experimento, provavelmente decorreu do baixo número de repetições (duas) utilizadas.

Gooding ${ }^{16}$ sugere a relação entre os teores de fibra e sacarose (FDN/POL) como importante variável na escolha de variedades de cana-de-açúcar para a alimentação de bovinos e Rodrigues, Primavesi e Esteves ${ }^{15}$ indicam valor máximo de 2,7 para esta relação. A baixa digestibilidade da fibra da cana-de-açúcar provoca acúmulo de material não-degradado no rúmen, limitando o consumo voluntário pelo mecanismo físico de repleção ruminal ${ }^{17}$ e comprometendo, desta 
forma, o consumo de energia pelo animal. Por isso, dever-se-ia escolher variedades que possuíssem menor relação FDN/POL, a fim de aumentar a DIVMS e evitar o efeito da fibra em limitar o consumo pelos animais. No entanto, este critério não leva em conta a variação existente na taxa de digestão da FDN, ou seja, na qualidade da fibra de genótipos de cana-deaçúcar, sendo este um importante fator que afeta o desempenho animal ${ }^{18}$.

O fato de não se ter evidenciado correlação entre DIVMS e relação FDN/POL, quando o corte foi realizado no mês de setembro (Tabela 4), com idade de corte de 15 meses, pode ser explicado pela menor amplitude existente nos valores de FDN/POL entre os genótipos colhidos em setembro $(2,1$ a 2,8$)$ do que em maio $(2,7$ a 5,8). Na colheita de maio, devido à grande variação nos teores de açúcar da planta inteira, boa parte da variação da DIVMS foi explicada pela variação dos teores de FDN/POL, sendo que genótipos com maior teor de açúcar também possuíam maior DIVMS. Entretanto, quando colhidos em setembro, houve pequena variação na relação FDN/POL entre os genótipos, assim a variação na DIVMS não pode ser explicada pela variação dos teores de FDN/POL, e a digestibilidade da fibra passou a ser mais importante para explicar a variação na DIVMS entre os genótipos. Tal fato fica ainda mais claro quando se observa que não houve correlação entre DIVMS e DIVFDN dos genótipos colhidos em maio (Tabela 3), porém houve forte correlação entre DIVMS e DIVFDN quando os genótipos foram colhidos em setembro (Tabela 4).

A DIVFDN se mostrou correlacionada apenas com o teor de LDA-FDN, mas não com os teores totais de FDN, LDA-MS ou POL, nem com a relação FDN/ POL, o que demonstra que a digestibilidade da fibra está relacionada principalmente com a qualidade e não com a quantidade desta fibra. Tal fato abre possibilidade para seleção genética de variedades de canade-açúcar especialmente direcionadas para a nutrição de ruminantes, que possuam fibra de melhor quali- dade (mais digestível), mas que, ao mesmo tempo, possuam maiores teores de açúcares solúveis (POL), atendendo também aos interesses da indústria sucroalcooleira.

Houve redução relativa no teor total de FDN de acordo com a época de corte (11 ou 15 meses), sem alteração no teor de LDA-MS. Avaliando variedades de cana-de-açúcar aos seis e aos 24 meses, Kung Jr. e Stanley ${ }^{19}$ também observaram redução no teor de FDN (68,30 para 52,60\%), enquanto a lignina aumentou de 6,3\% para 7,3 \%, respectivamente. Entretanto, Azevêdo et al. ${ }^{6}$ observaram aumento nos teores de FDN do primeiro para o segundo corte, seguido por redução nos cortes subsequentes. Os autores observaram também diminuição no teor de lignina da planta toda de $14,1 \%$, no primeiro corte, para $13,0 \%$ nos cortes subsequentes.

Segundo Brugnaro et al. ${ }^{20}$, à medida que diminui a atividade vegetativa da cana-de-açúcar, com o avanço do estágio de maturação, os teores de açúcar (BRIX e POL) crescem até um máximo e, depois, voltam a cair. Avaliando três variedades de cana, Landell et al. ${ }^{21}$ observaram aumento no teor de POL da cana-soca até a colheita de final de agosto, com pequena redução no teor de POL entre a colheita de agosto e de outubro. No entanto, tal redução não foi observada para as mesmas variedades no primeiro ano de colheita (cana-planta). Maule, Mazza e Martha $\mathrm{Jr}^{22}$, ao avaliarem nove cultivares colhidos em maio, agosto e outubro, observaram aumento no teor de POL para a colheita em outubro e Fernandes et al. ${ }^{23}$, também avaliando a composição da cana em três idades de corte, observaram elevação linear do teor de BRIX. Esta importante característica explica os resultados obtidos neste trabalho, pois o aumento no teor de açúcar produz efeito de diluição da FDN na matéria seca.

OS dados encontrados sugerem que a parede celular continua sendo lignificada com o avanço da maturidade, porém devido ao acúmulo de açúcares no colmo, o valor de FDN é reduzido e o teor de LDA-MS 
não se altera, causando redução da DIVFDN com o avançar da idade.

O aumento na DIVMS pode ser explicado pelo acúmulo de sacarose, a qual é prontamente digestível. O efeito de diluição da FDN pelos crescentes teores de açúcares solúveis melhora o valor nutritivo da canade-açúcar como planta forrageira, uma vez que a fibra da cana apresenta como característica baixa digestibilidade e os açúcares são considerados prontamente digestíveis ${ }^{3}$.

Os maiores valores de PB presentes na fração folha concordam com os resultados encontrados por Rodrigues, Primavesi e Esteves ${ }^{15}$, que observaram valores de PB variando de 0,72 a 1,35\% MS, e de 4,61 a 6,05\% MS para colmos e folhas, respectivamente. A redução observada nos teores de $\mathrm{PB}$ da planta inteira, da primeira para a segunda época de corte, está de acordo com Andrade et al. ${ }^{1}$, que comparando 60 genótipos de cana-de-açúcar cortados aos 12 e aos 18 meses observaram redução no teor de $\mathrm{PB}$ de 2,59 para $2,34 \%$, respectivamente. Durante a maturação, ocorre maior desenvolvimento dos colmos em relação ao número de folhas e, como a PB da cana-de-açúcar está concentrada principalmente em suas folhas, a maior relação colmo: folha irá causar redução relativa no teor de $\mathrm{PB}$ da planta.

É importante conhecer a qualidade da cana, em termos de fibra, conteúdo de açúcares e relação fibra/açúcar. Rodrigues, Primavesi e Esteves ${ }^{15}$ comentaram que variedades que apresentam menor teor de FDN, permitem ao animal maior consumo de energia, do que variedades com teor

\section{Referências}

1. ANDRADE, J. B.; FERRARI JUNIOR, E.; POSSENTI, R. A.; OTSUK, I. P.; ZIMBACK, L.; LANDELL, M. G. A. Composição química de genótipos de cana-de-açúcar em duas idades, para fins de nutrição animal. Bragantia, Campinas, v. 63, n. 3, p. 341-349, 2004.

2. FREITAS, A. W. P.; PEREIRA, J. C.; ROCHA, F. C.; DETMANN, E.; BARBOSA, M. H. P.; RIBEIRO, M. D.; COSTA, M. G. Avaliação da divergência nutricional de genótipos de cana-de- de açúcar um pouco melhor, porém com maior teor de FDN. A digestibilidade tem sido normalmente utilizada como variável de qualidade, indicando a proporção do alimento que está apta a ser utilizada pelo animal ${ }^{24}$. No entanto, em um trabalho utilizando cana descascada, com maior DIVMS, Preston ${ }^{25}$ não observou melhoria no ganho de peso dos animais, demonstrando que a DIVMS não deve ser considerada isoladamente como parâmetro para escolha de variedades de cana-de-açúcar para a alimentação animal. A taxa de digestão ruminal da FDN da fração colmo é uma característica importante a determinar o valor nutritivo da cana-de-açúcar.

\section{Conclusão}

$\mathrm{O}$ avanço da maturidade promoveu aumento nos teores de sacarose e digestibilidade da matéria seca, e queda na digestibilidade da FDN e na relação FDN/ POL da planta inteira de cana-de-açúcar. A fração colmo de cana-de-açúcar apresentou maior digestibilidade in vitro da MS e menor digestibilidade in vitro da FDN do que a fração folha. A DIVFDN não se mostrou correlacionada com o teor de sacarose ou relação FDN/POL.

Os dados deste artigo indicam não ser esperado que a seleção de genótipos com maior DIVFDN do colmo altere o teor de açúcar do mesmo. Desta forma, é possível o desenvolvimento de programas de melhoramento genético da cana-de-açúcar que atendam aos interesses tanto da nutrição de ruminantes, quanto da indústria sucroalcooleira.

açúcar (Saccharum spp.). Revista Brasileira de Zootecnia, v. 35, n. 1, p. 229-236, 2006.

3. LANDELL, M. G. A.; CAMPANA, M. P.; RODRIGUES, A. A.; BATISTA, L. A. R.; FIGUEIREDO, P.; SILVA, M. A.; BIDOIA, M. A. P.; ROSSETO, R.; MARTINS, A. L.; KANTHACK, R. A. O.; CAVICHIOLI, J. C.; VASCONCELLOS, A. C. M.; XAVIER, M. A. A variedade IAC86-2480 como nova opção de canade-açúcar para fins forrageiros: manejo de produção e uso na 
alimentação animal. Campinas: Instituto Agronômico, 2002. 39 p. (Série Tecnologia APTA, boletim técnico IAC, 193).

4. BORGES, A. L. C. C.; PEREIRA, L. G. R. Cana-de-açúcar como volumoso para bovinos. In: MARQUES, D. C. Criação de bovinos. 7. ed. Belo Horizonte: Consultoria Veterinária e Publicações, 2003. p. 221-224.

5. CASLER, M. D. Breeding for increased forage quality. In: LAMKEY, K. R.; LEE, M. Plant breeding: arnel hallauer international symposium. Oxford, UK: Blackwell Publishers, 2006. p. 323-334.

6. AZEVÊDO, J. A. G.; PEREIRA, J. C.; CARNEIRO, P. C. S.; QUEIROZ, A. C. de; BARBOSA, M. H. P.; FERNANDES, A. M.; RENNÓ, F. R. Avaliação da divergência nutricional de variedades de cana-de-açúcar (Saccharum spp.). Revista Brasileira de Zootecnia, v. 32, n. 6, p. 1431-1442, 2003.

7. PEREIRA, E. S.; QUEIROZ, A. C.; PAULINO, M. F.; CECON, P. R.; VALADARES FILHO, S. C.; MIRANDA, L. F.; ARRUDA, A. M. V. de; FERNANDES, A. M.; CABRAL, L. S. Fontes nitrogenadas e uso de Sacharomyces cerevisiae em dietas à base de cana-de-açúcar para novilhos: consumo, digestibilidade, balanço nitrogenado e parâmetros ruminais. Revista Brasileira de Zootecnia, v. 30, n. 2, p. 563-572, 2001.

8. AOAC. ASSOCIATION OF OFFICIAL ANALYTICAL CHEMISTS. Official methods of analysis. 10. ed. Washington: AOAC International, 1980. $1015 \mathrm{p}$.

9. VAN SOEST, P. J.; ROBERTSON, J. B.; LEWIS, B. A. Methods for dietary fiber neutral detergent fiber and non-starch polysaccharides in relation to animal nutrition. Journal of Dairy Science, v. 74, p. 3583-3597, 1991.

10.GOERING, H. K.; VAN SOEST, P. J. Forage fiber analyses: apparatus, reagents, procedures, and some applications. Washington: USDA, 1970. 20 p. (Agriculture Handbook, 379).

11. FERNANDES, A. C. Cálculos na agroindústria da cana-deaçúcar. Piracicaba: STAB, 2003. 240 p.

12.SAS. STATISTICAL ANALISYS SYSTEN. SAS user's guide: statistics. Version 8.0. Cary: SAS Institute, 2000.

13.BANDA, M.; VALDEZ, R. E. Effect of stage of maturity on nutritive value of sugar cane. Tropical Animal Production, v. 1, n. 1, p. 94-97, 1976 .

14.SALLAS, M.; AUMONT, G.; BIESSY, G.; MAGNIE, E. Effect of variety, stage of maturity and nitrate fertilization on nutritive values of sugar canes. Animal Feed Science and Technology, v. 39 , p. $265-277,1992$.
15.RODRIGUES, A. A.; PRIMAVESI, O.; ESTEVES, S. N. Efeito da qualidade de variedades de cana-de-açúcar sobre seu valor como alimento para bovinos. Pesquisa Agropecuária Brasileira, v. 32, n. 12, p. 1333-1338, 1997.

16.GOODING, E. G. B. Effect of quality of cane on its value as livestock feed. Tropical Animal Production, v. 7, n. 1, p. 7291, 1982.

17. CASLER, M. D. Divergent selection for two measures of intake potential in smooth bromegrass. Crop Science, v. 42, n. 5, p. 1427-1433, 2002.

18. OBA, M.; ALLEN, M. S. Evaluation of the importance of the digestibillity of neutral detergent fiber from forage: effects on dry matter intake and milk yield of dairy cows. Journal of Dairy Science, v. 82, n. 3, p. 589-596, 1999.

19.KUNG JR., L.; STANLEY, R. W. Effects of stage of maturity on the nutritive value of whole-plant sugarcane preserved as silage. Journal of Animal Science, v. 54, p. 689-696, 1982.

20.BRUGNARO, C.; HEISE, C. E.; PERES, F. C.; GIL, O. F. Maximização da produção de uma usina de açúcar. Brasil Açucareiro, v. 106, n. 5/6, p. 2-8, 1988.

21.LANDELL, M. G. A.; ALVAREZ, R.;ZIMBACK, L.; CAMPANA, M. P.; SILVA, M. A.; PEREIRA, J. C. V. N A.; PERECIN, D.; GALLO, P. B.; MARTINS, A. L. M.; KANTHACK, R. A. D.; FIGUEIREDO, P.; VASCONCELOS, A. C. M. Avaliação final de clones IAC de cana-de-açúcar da série 1982, em latossolo roxo da região de Ribeirão Preto. Bragantia, Campinas, v. 58, n. 2, p. 269-280, 1999.

22.MAULE, R. F.; MAZZA, J. A.; MARTHA JR., G. B. Produtividade agrícola de cultivares de cana-de-açúcar em diferentes solos e épocas de colheita. Scientia Agricola, v. 58, n. 2, p. 295-301, 2001.

23. FERNANDES, A. M.; QUEIROZ, A. C.; PEREIRA, J. C.; LANA, R. P.; BARBOSA, M. H. P.; FONSECA, D. M. da; DETMANN, E.; CABRAL, L. S.; PEREIRA, E. S.; VITTORI, A. Composição químico-bromatológica de variedades de cana-de-açúcar (Saccharum spp L.) com diferentes ciclos de produção (precoce e intermediário) em três idades de corte. Revista Brasileira de Zootecnia, v. 32, n. 4, p. 977-985, 2003.

24. VAN SOEST, P. J. Nutritional ecology of the ruminant. 2. ed. Ithaca: Cornell University Press, 1994. 476 p.

25.PRESTON, T. R. Nutritional limitations associated with the feeding of tropical forages. Journal of Animal Science, v. 54, n. 4 , p. $877-884,1982$. 